\title{
MORPHOMETRIC ANALYSIS OF LATERAL TARSAL ARTERY AND ITS SURGICAL IMPORTANCE
}

\author{
Arun P Chepte *, M V Ambiye.
}

Department of Anatomy, Rural Medical College, Pravara Institute of Medical Sciences (Deemed University), Loni Tal, Rahata Dist, Ahmednagar (MS), India.

\section{ABSTRACT}

The present study was carried out on 60 cadaveric lower limbs in Dept. of Anatomy, TNMC, Mumbai. Lateral tarsal artery (LTA) was studied with regard to origin, course, branches and its length \& external diameter were noted. LTA was present in 59 cases. Dorsal metatarsal arteries in 7 cases arose from LTA. The mean length was $34.16 \pm 0.22 \mathrm{~mm}$. The mean external diameter at its origin was $2.09 \pm 0.33 \mathrm{~mm}$. Lateral tarsal artery is useful as an artery flap to repair web contractures and plays a great role in forefoot defect surgeries.

KEY WORDS: Dorsalis Pedis Artery, Lateral Tarsal Artery, Foot Surgery.

Address for Correspondence: Dr. Arun Chepte, Department of Anatomy, Rural Medical College, Pravara Institute of Medical Sciences, (Deemed University), Loni Tal, Rahata Dist, Ahmednagar (MS), India. E-Mail: drarunchepte@gmail.com

\section{Access this Article online}

\section{Quick Response code}

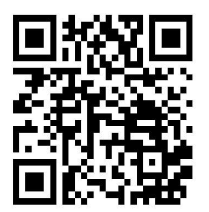

DOI: $10.16965 /$ ijar.2017.281
Web site: International Journal of Anatomy and Research

ISSN 2321-4287

www.ijmhr.org/ijar.htm

Received: 03 June 2017

Accepted: $18 \mathrm{Jul} 2017$

Peer Review: 04 June 2017

Revised: None
Published (O): 31 Aug 2017

Published (P): 31 Aug 2017

\section{INTRODUCTION}

Lateral tarsal artery is a branch of dorsalis pedis artery. It supplies dorsum of foot. It ends by supplying overlying muscles and underlying metatarsals [1]. It's a significant vascular channel of foot. Forefoot is portion of the foot distal to the tarsometatasal joint and is the major weight bearing portion in standing. A lateral tarsal (LT) flap is a reasonable option for treating traumatic forefoot skin and soft tissue defects [2]. Bypass to tarsal arteries plays important role in limb salvage of ischemic limbs in diabetic patients. Knowledge of this artery is helpful in limb amputation surgeries [3].

\section{MATERIALS AND METHODS}

The study was conducted in the department of anatomy in TNMC \& BYL Nair Ch. Hospital, Mumbai. The study was carried out on 60 lower limbs of unknown sex \& age from the department of Anatomy and dorsum of foot was dissected.

The long extensor tendons were severed. Dorsalis pedis artery identified, its branches were traced (Fig. 1). Lateral tarsal artery deep to tendons was identified and traced, and its length \& external diameter were measured.

Length of the lateral tarsal artery: It was measured as the distance between its origin i.e. point of origin from DPA to its termination i.e. when it joins any other artery to form anastomosis with the help of calibrated digital vernier caliper.(Fig. 2)

\section{External diameter of the lateral tarsal artery:}

It was measured at its origin from dorsalis pedis artery with the help of calibrated digital vernier caliper. (Fig. 3) 
Fig 1: Dorsalis pedis artery \& it branches (Note Lateral tarsal artery)

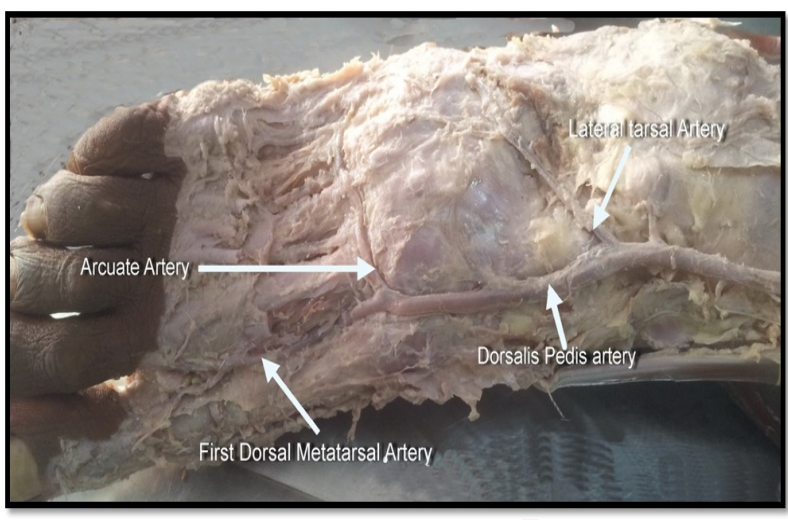

Fig. 2: Measurement of the length of lateral tarsal artery.

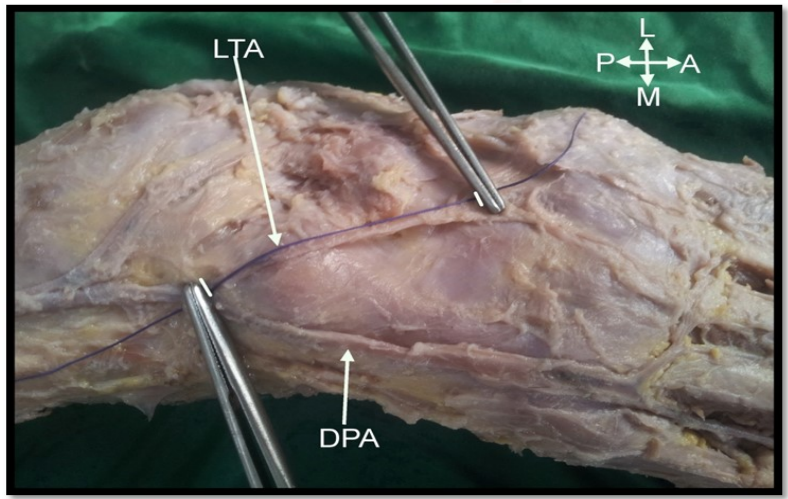

Fig. 3: Measurement of the external diameter of latera tarsal artery at the origin.

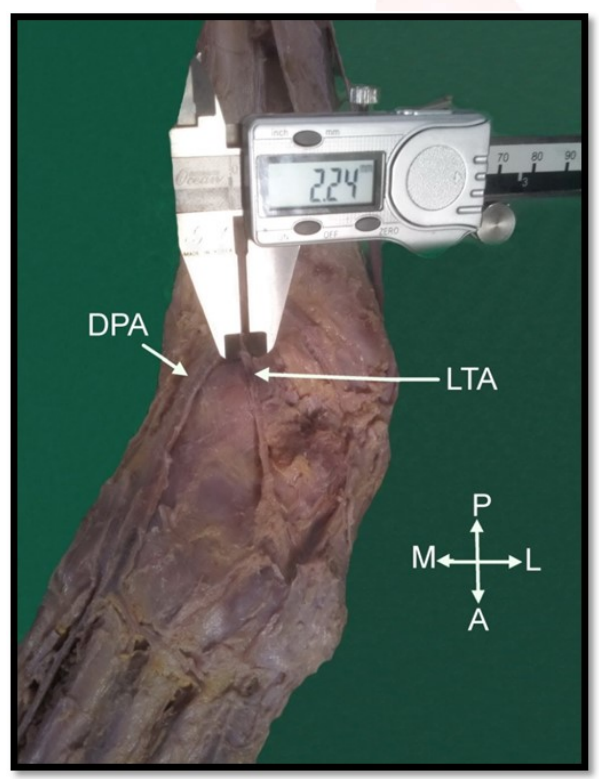

Fig. 4: Absent lateral tarsal artery and arcuate artery.

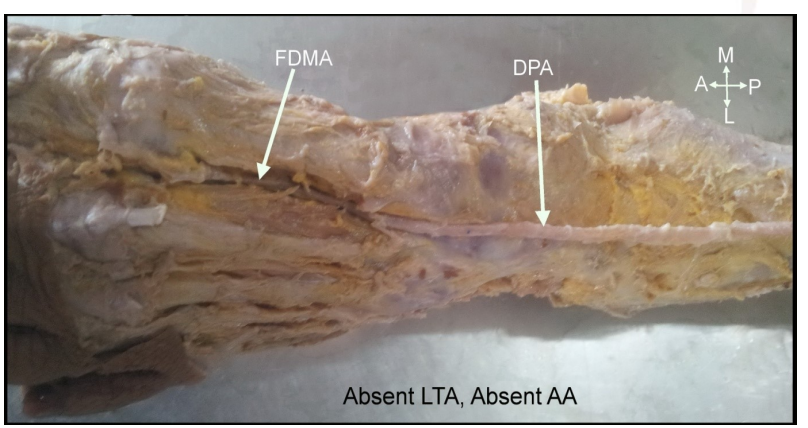

Fig. 5: Origin of $2^{\text {nd }}$ DMA from DPA, LTA giving $3^{\text {rd }} \& 4^{\text {th }}$ DMA

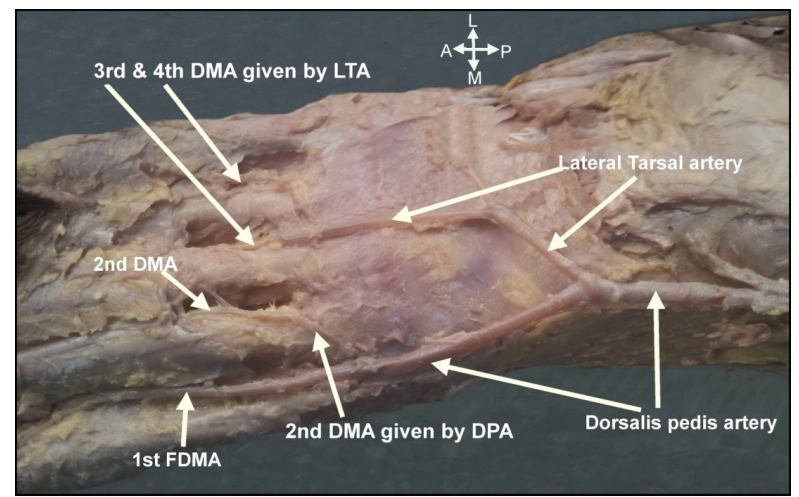

\section{OBSERVATIONS AND RESULTS}

In the present study, Lateral tarsal artery (LTA) was present in 59 cases (98.33\%). It was absent in $1(1.66 \%)$ case. Normally LTA does not give dorsal metatarsal arteries (DMA) 1 however in the present study in 7 cases (11.66\%) LTA gave DMA's.

The mean length is $34.16 \pm 0.22 \mathrm{~mm}$. It ranges between $12.68 \mathrm{~mm}-57.5 \mathrm{~mm}$.

The mean external diameter of LTA at its origin is $2.09 \pm 0.33 \mathrm{~mm}$. It ranges between $1.11 \mathrm{~mm}-$ $2.93 \mathrm{~mm}$. (Table 1)

Maximum number (76.27\%) of lower limbs were having average length of LTA in the range of $25.48 \mathrm{~mm}$ - $44.69 \mathrm{~mm}$ and minimum number (13.55\%) of lower limbs were having the length less than $25.48 \mathrm{~mm}$ and $10.16 \%$ had length more than $44.69 \mathrm{~mm}$. (Table 2)

Maximum number (88.13\%) of lower limbs were having the external diameter of LTA at its origin in the range of $1.63 \mathrm{~mm}-2.67 \mathrm{~mm}$ and $8.47 \%$ of lower limbs were having E.D of less than 1.63 $\mathrm{mm}$ and $3.38 \%$ had E.D more than 2.67 $\mathrm{mm}$.(Table 3)

Table 1: Descriptive statistics of measurements of the lateral tarsal artery:

\begin{tabular}{|c|c|c|c|c|}
\hline \multicolumn{5}{|c|}{ Descriptive statistics (in mm) } \\
\hline & Min & Max & Mean & S.D \\
\hline Length & 12.68 & 57.5 & 34.16 & 8.22 \\
\hline E.D at origin & 1.11 & 2.93 & 2.09 & 0.33 \\
\hline
\end{tabular}

(LTA - Lateral Tarsal Artery, E.D - External Diameter)

\begin{tabular}{r|c|c|c|}
\cline { 2 - 4 } Table 2: & \multicolumn{3}{|c|}{ Distribution by groups } \\
\cline { 2 - 4 } $\begin{array}{c}\text { Distribution } \\
\text { of study group }\end{array}$ & Length (in mm) & $\begin{array}{c}\text { No. of } \\
\text { Samples }\end{array}$ & $\begin{array}{c}\text { Percentage } \\
\text { (\%) }\end{array}$ \\
\cline { 2 - 4 } $\begin{array}{c}\text { according to } \\
\text { length of LTA. }\end{array}$ & $<25.48$ & 8 & 13.55 \\
\cline { 2 - 4 } (LTA - Lateral & $25.48-44.69$ & 45 & 76.27 \\
\cline { 2 - 4 } Tarsal Artery) & $>44.69$ & 6 & 10.16 \\
\cline { 2 - 4 } & &
\end{tabular}




\begin{tabular}{l|c|c|c|}
\cline { 2 - 4 } Table 3: Distribution & \multicolumn{3}{|c|}{ Distribution by groups } \\
\cline { 2 - 4 } of study group & E.D (in mm) & No. of & Sercentage (\%) \\
\cline { 2 - 4 } according to external & $<1.63$ & 5 & 8.47 \\
\cline { 2 - 4 } diameter of lateral & $1.63-2.67$ & 52 & 88.13 \\
\cline { 2 - 4 } tarsal artery. & $>\mathbf{2 . 6 7}$ & 2 & 3.38 \\
\hline
\end{tabular}

(LTA - Lateral Tarsal Artery, E.D - External Diameter)

\section{DISCUSSION}

Lateral tarsal artery arises from dorsalis pedis artery, supplies tarsals and metatarsals. It also gives some muscular branches to overlying short muscles of dorsum of foot. It ends by anastomosing with small branches of dorsalis pedis artery.

In the present study, LTA was present in 59 cases (98.33\%). It was absent in $1(1.66 \%)$ case. (Fig 4)

Normally LTA does not give Dorsal metatarsal arteries(DMA) 1 however in the present study in 7 cases (11.66\%) LTA gave DMA's. (Fig. 5)

Keely cassidy \& MA Khan (2011)[4] in a study of 18 feet noted the lateral tarsal artery present in $94 \%$ of the cadaveric feet and absent in $6 \%$.

Measurement of length of the lateral tarsal artery : ( In $\mathrm{mm})$

In the present study the length of the lateral tarsal artery ranged from $12.68 \mathrm{~mm}$ to $57.5 \mathrm{~mm}$ with a mean of $34.16 \pm 8.22 \mathrm{~mm}$.

EM El-Saeed et al. (2008) [5] found the length of the lateral tarsal artery in the range $18 \mathrm{~mm}$ to $37 \mathrm{~mm}$ with a mean of $27 \pm 5.7 \mathrm{~mm}$ (Table 4 ).

Table 4: Comparison of the length of the lateral tarsal artery with the previous studies.

\begin{tabular}{|c|c|c|c|c|c|c|}
\hline Study & Year & Sample & Minimum & Maximum & Mean & S.D \\
\hline EM El-Saeed et al. [5] & 2008 & 20 & 18 & 37 & 27 & 5.7 \\
\hline Present Study & 2014 & 60 & 12.68 & 57.5 & 34.16 & 8.22 \\
\hline
\end{tabular}

Findings of the present study for length of the LTA were higher than EM El-Saeed et al. (2008) [5]. This can be attributed to racial, ethnic and population diversity.

Measurement of external diameter of the lateral tarsal artery : ( $\mathrm{ln} \mathrm{mm}$ )

In present study the external diameter of lateral tarsal artery ranged from 1.11 to $2.93 \mathrm{~mm}$ with a mean of $2.09 \pm 0.33 \mathrm{~mm}$.

Findings of the present study for external diameter of the LTA were closely related with EM
El-Saeed et al. (2008) [5]. (Table 5)

Table 5: Comparison of the external diameter of the lateral tarsal artery with the previous studies:

\begin{tabular}{|c|c|c|c|c|c|c|}
\hline Author & Year & Sample & Minimum & Maximum & Mean & S.D \\
\hline EM El-Saeed et al. [5] & 2008 & 20 & 1.2 & 2.8 & 2.1 & 0.59 \\
\hline Present Study & 2014 & 60 & 1.11 & 2.93 & 2.09 & 0.33 \\
\hline
\end{tabular}

(E.D- External diameter, LTA-Lateral tarsal artery, Minminimum, Max-Maximum, S.D-Standard deviation)

Repair of forefoot defects remain a major challenge in surgical practice, especially in terms of reconstructing forefoot appearance and function.

Lateral tarsal artery flap is an artery flap based on septocutaneous or musculocutaneous perforators supplied by the lateral tarsal artery. Suitable vessel diameter, similar color and texture to hand, helps in its utility as a flap in repair of web contracture, a complication of hand injury [6].

A lateral tarsal (LT) flap has good contour, elasticity, and durability similar to the forefoot and thus is a reasonable option for treating traumatic forefoot skin and soft tissue defects or operative wounds [2].

Lateral tarsal (LT) flap with a reversed DPA pedicle is a reliable and effective technique for covering complex forefoot defects. The DPA pedicle used in flap is anatomically constant and well perfused [7].

Distal foot reconstruction, especially of wounds over the toes, has always been a challenging problem in plastic surgery. The Extensor digitorum brevis flap with intact lateral tarsal artery can be used for distal foot defects [8].

\section{CONCLUSION}

Lateral tarsal artery is a branch of DPA which supply bones \& muscles of the dorsum of forefoot. LTA flap gives a great choice to surgeons for forefoot defects. Variations of lateral tarsal artery are important and can change the outcome of foot surgeries. Hence it's imperative for surgeons to have thorough knowledge of lateral tarsal artery.

\section{ABBREVIATIONS}

DPA- Dorsalis pedis artery

LTA- Lateral tarsal artery

DMA- Dorsal metatarsal artery

FDMA- First dorsal metatarsal artery 


\section{Conflicts of Interests: None}

\section{REFERENCES}

[1]. Susan Standring. Gray's anatomy. The Anatomical basis of clinical practice, 40th edition, London, Churchill Livingstone Elsevier, Ch. IX, Pg.2654-55.

[2]. Miao W, Liu Z, Xu C. [Repair of forefoot skin and soft tissue defect with reverse lateral tarsal artery flap] [in Chinese].Zhongguo Xiu Fu Chong Jian Wai Ke Za Zhi. 2010;24:53-56.

[3]. Aulivola, B, Pomposelli, F B Journal of Cardiovascular Surgery; Jun 2004; 45, 3; ProQuest Medical Library pg. 203

[4]. Keely Cassidy and MA Khan. Anatomic variations of the dorsalis pedis artery: A cadaveric study. (The FASEB Journal. 2011;25:Ib2

[5]. Ebrahim M.El Saeed, Amal Abd El-monisif Madiha A. El-Sayed, Nancy M.Aly, Naser A. Gezlan. Anatomical study of dorsalis pedis artery and its surgical importance in Reconstr.surg: Alexandria Journal of medicine 2008;44(2):557-571.
[6]. $\mathrm{H}$ lang Dong, Wang Hong - gang, Zhao Cheng - yi and W Wei- zhi, An alternative approach in the treatment of thumb web contracture skin defects : lateral tarsal artery flap, Chinese Medical Journal, 2009;122(18):2133- 2137.

[7]. Dehao Fu, MD, Liyi Zhou, MD, Shuhua Yang, MD and Baojun Xiao, MD Surgical Technique: Repair of Forefoot Skin and Soft Tissue Defects Using a Lateral Tarsal Flap With a Reverse Dorsalis Pedis Artery Pedicle: A Retrospective Study of 11 Patients. Clin Orthop Relat Res. Jan 2013;471(1):317-323.

[8]. Ashok Raj Koul, Rahul K Patil and Vinoth Kumar Philip, Coverage of defects over toes with distally based local flaps: A report of four cases, Indian Journal of Plastic Surgery 2008;41(1):62-66.

How to cite this article:

Arun P Chepte, $M \vee$ Ambiye. MORPHOMETRIC ANALYSIS OF LATERAL TARSAL ARTERY AND ITS SURGICAL IMPORTANCE. Int J Anat Res 2017;5(3.2):4187-4190. DOI: 10.16965/ijar.2017.281 